\title{
The Effectiveness of a Proposed Training Program based on Professional Competencies in the Light of International Standards in Developing the Teaching Performance of Mathematics Teachers at the Intermediate Stage in Kuwait
}

Waleed Mohammad Qasem, Nashaat Abdelaziz Abdelqader Baioumy, Nooraihan Binti Ali, Tasnim Binti Mohd Annuar, Salah Ahmad Fauad Salah

To Link this Article: http://dx.doi.org/10.6007/IJARBSS/v11-i12/12066 DOI:10.6007/IJARBSS/v11-i12/12066

Received: 05 October 2021, Revised: 07 November 2021, Accepted: 29 November 2021

Published Online: 23 December 2021

In-Text Citation: (Qasem et al., 2021)

To Cite this Article: Qasem, W. M., Baioumy, N. A. A., Ali, N. B., Annuar, T. B. M., \& Salah, S. A. F. (2021). The Effectiveness of a Proposed Training Program based on Professional Competencies in the Light of International Standards in Developing the Teaching Performance of Mathematics Teachers at the Intermediate Stage in Kuwait. International Journal of Academic Research in Business and Social Sciences, 11(12), 2674- 2695.

Copyright: (C) 2021 The Author(s)

Published by Human Resource Management Academic Research Society (www.hrmars.com) This article is published under the Creative Commons Attribution (CC BY 4.0) license. Anyone may reproduce, distribute, translate and create derivative works of this article (for both commercial and non0-commercial purposes), subject to full attribution to the original publication and authors. The full terms of this license may be seen at: http://creativecommons.org/licences/by/4.0/legalcode

Vol. 11, No. 12, 2021, Pg. 2674- 2695

Full Terms \& Conditions of access and use can be found at http://hrmars.com/index.php/pages/detail/publication-ethics 


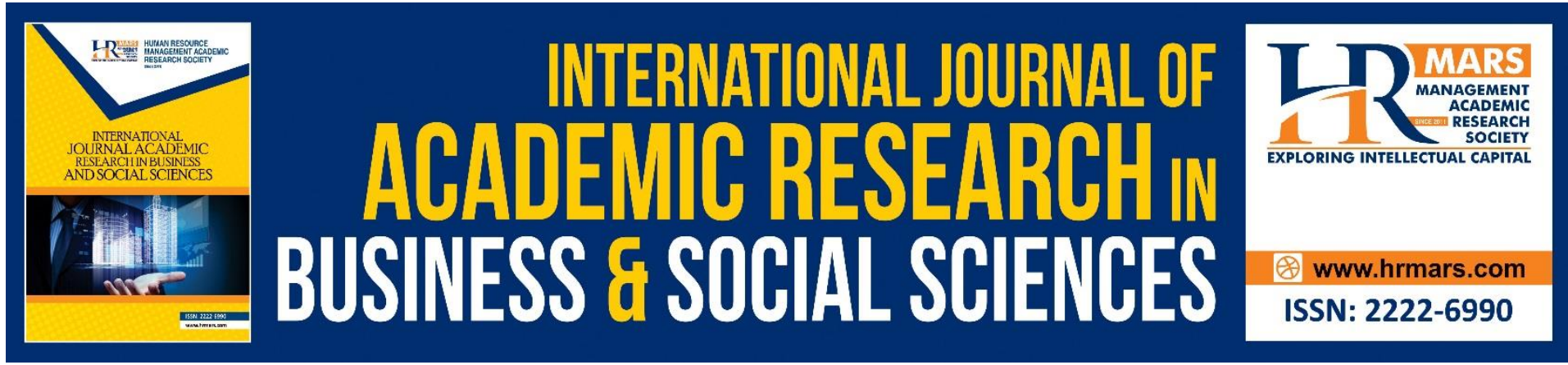

\title{
The Effectiveness of a Proposed Training
} Program based on Professional Competencies in the Light of International Standards in Developing the Teaching Performance of Mathematics Teachers at the Intermediate Stage in Kuwait

\author{
${ }^{1}$ Waleed Mohammad Qasem, ${ }^{2}$ Nashaat Abdelaziz Abdelqader \\ Baioumy, ${ }^{3}$ Nooraihan Binti Ali, ${ }^{4}$ Tasnim Binti Mohd Annuar, \\ ${ }^{5}$ Salah Ahmad Fauad Salah \\ ${ }^{1,4}$ Faculty of Islamic Contemporary Studies, University Sultan Zainal Abidin, Terengganu, \\ Malaysia, ${ }^{5}$ Faculty of Graduate Studies, Cairo University \\ Email: nashaatbaioumy@unisza.edu.my
}

\begin{abstract}
The contemplator of mathematics teaching notes that the educational outcomes have not reached the acceptable level in the State of Kuwait; It is punctuated by many problems, represented by the low educational attainment of students, so the current study aimed to reveal the effectiveness of a proposed training program based on professional competencies in the light of international standards in developing the teaching performance of mathematics teachers at the intermediate stage in Kuwait. the descriptive analytical approach, the constructivist approach, and the quasi-experimental approach. To achieve the objectives of the study, a teaching competency questionnaire, a note card, and a training program based on professional competencies were prepared. The study sample consisted of 30 middle school mathematics teachers (the eighth-grade teachers). The study tools were applied to them, appropriate statistical analyzes were performed and quantitative results were extracted. The results of the study showed that the professional competencies that mathematics teachers at the intermediate stage in the State of Kuwait should master in light of international standards came within a medium degree of proficiency; The field of teaching implementation competencies came in the first place, and in the second place came the field of teaching planning competencies. In the third and final place came the field of teaching evaluation competencies. The results also showed that there were statistically significant differences at the significance level $(\alpha=0.05)$ between the scores of the quasi-experimental group members on the teaching performance in favor of the post-measurement. The study recommended the necessity of paying attention to the professional competencies of mathematics educators in the intermediate stage, by holding specialized in-service courses that include theoretical and practical mathematical and educational knowledge and information. And the need to pay
\end{abstract}


attention to the professional growth of middle school mathematics teachers and the integration of knowledge and skills, in order to reach a high level of competence necessary for teaching mathematics.

Keywords: Training Program, Professional Competencies, International Standards, Teaching Performance.

\section{Introduction}

The world today is facing many challenges as a result of the knowledge explosion that is witnessing this century, as the growth of knowledge is multiplying at a speed that humanity has not known before. Interest in scientific study to keep pace with the development and change in the functions of education.

Azeem \& Omar (2018) indicates that the teacher is the important component in the educational process, and it is necessary for the teacher to play roles that contribute to improving his teaching skills to reflect positively on the knowledge, skills, attitudes, and values that his students acquire. Hence, the teacher's teaching competencies are defined as "the knowledge, skills, and attitudes that enable the teacher to carry out his classroom tasks with maximum effectiveness." Tennessee State Department of Education, 2016). The identification of these competencies through research has led to the development of teaching frameworks and standards such as the Framework for Teaching Competencies (FfT) and the National Council for Professional Teaching Standards (NBPTS). which emphasize the need to train teachers to provide them with teaching competencies and then evaluate them in all academic subjects, especially mathematics (Hu, et al., 2008)). The NCTM (1995) also introduced four sets of mathematics standards in the areas of curriculum, teaching, and assessment, and in April 2000 (NCTM), the National Council of Teachers of Mathematics issued Principles and Standards for School Mathematics that have had worldwide influence in establishing a vision for school mathematics based on Student understanding and problem solving. Hence, standards are defined as: "Describing what individuals can do and what can be measured" (Nair, 2017: 6); Hiebert (2003) concluded that standards-based programs were more effective in teaching and learning mathematics appropriately.

The 2015 PISA study focused primarily on students' achievement in mathematics and found that the mathematics curriculum did not meet international standards, as students' performance was poor in mathematical tasks in many countries, especially in the State of Kuwait, and this is due to the low level of performance math teachers. This decline may be attributed to the weakness in their professional competencies to teach mathematics, and based on the foregoing, the current study seeks to reveal the impact of the effectiveness of a proposed training program based on professional competencies in the light of international standards in developing the teaching performance of mathematics teachers at the intermediate stage in Kuwait.

\section{Problem of the Study}

Despite the comprehensive and continuous development efforts in the State of Kuwait aimed at improving educational outcomes and raising the level of their quality, the contemplator of mathematics teaching notes that educational outcomes in mathematics have not reached the acceptable level. It is punctuated by many problems, represented in the low educational attainment of students. This is evident in the international study (Timss) conducted in 2015, on eighth grade students, and was applied to (39) countries, including the State of Kuwait; The results of this study showed that the achievement of Kuwaiti students is 
low in mathematics, and Kuwait ranked 33 out of 39 countries that participated in the international test.

This is confirmed by Zeynep's study (2019) that mathematics teachers lack the teaching professional competencies they need to teach mathematics effectively, due to their lack of experience, which negatively affects the educational attainment of their students. This is indicated by $\mathrm{Li}$ and others ( $\mathrm{Li}$ et al., 2018) that the professional competence of mathematics teachers in this field is relatively weak.

Studies (Julia \& Lars, 2017) confirm; Heath, 2017; Jana, et al., 2017) that the lack of teacher knowledge content for teaching skills and their applications in mathematics is one of the main factors in not seeing expected achievement gains despite efforts to reform mathematics education; Therefore, they recommend that mathematics teachers should be trained to provide them with the teaching skills they need in their classrooms through in-service training programs.

Because of the importance of the role of the mathematics teacher and his possession of skills in the process of planning, implementing and evaluating the teaching process and his professional growth, it was necessary to develop his performance and increase his effectiveness in performing his teaching tasks. Therefore, this study came to investigate the effectiveness of a proposed training program based on professional competencies in the light of international standards in developing the teaching performance of mathematics teachers at the intermediate stage in Kuwait.

\section{Study Questions}

The study aims to build a proposed training program based on professional competencies in light of international standards in developing the cognitive achievement and teaching performance of mathematics teachers at the intermediate stage in Kuwait. Therefore, the research sought to answer the following research questions:

1- What are the professional competencies that middle school mathematics teachers in the State of Kuwait should master in light of international standards?

2- What is the proposed training program based on professional competencies in light of international standards for developing the teaching performance of mathematics teachers at the intermediate stage in Kuwait?

3- What is the effectiveness of the proposed training program based on professional competencies in light of international standards in developing the teaching performance of middle school mathematics teachers?

\section{Objectives of the Study}

The study aims to achieve the following objectives:

1- Determining the professional competencies that mathematics teachers at the intermediate stage in the State of Kuwait should master.

2- Building the proposed training program based on professional competencies in the light of international standards in developing the teaching performance of mathematics teachers at the intermediate stage in the State of Kuwait.

3- Demonstrating the effectiveness of the proposed training program based on professional competencies in the light of international standards in developing the teaching performance of mathematics teachers at the intermediate stage in the State of Kuwait. 


\section{Importance of the Study}

The importance of the theoretical and applied study lies in the following:

The study sought to determine the necessary professional competencies for mathematics teachers in light of international standards in the State of Kuwait, in addition to providing a theoretical framework on the foundations and trends of building training programs to benefit mathematics supervisors in teacher training in light of recent experiences and contemporary trends.

The importance of teachers having the skills of teaching performance; Therefore, the best courses, educational aids, activities and school buildings, despite their importance, will not achieve the desired educational goals unless there is a teacher with teaching skills in the light of international standards by which he can provide his students with diverse experiences. The importance of applied research comes in building tools with psychometric properties Reliable as the Teaching Performance Note Card that a supervisor can use to assess the mathematics teacher's performance.

\section{Limitations of the Study}

This research is objectively limited to the following:

1- Objective limits: Preparing a program to develop the following professional competencies: (lesson planning, implementation, and evaluation) for middle school mathematics teachers in the State of Kuwait. In other words, the generalization of the results of the study is limited to these three competencies only. The study was limited to the application of professional competencies to a unit of the mathematics book for the eighth grade (engineering transformations), which was approved by the Ministry of Education in the State of Kuwait for the year (2020/2021).

2- Spatial limits: It includes all middle school teachers for the eighth grade in the Capital Education District in Kuwait.

3- Time limits: The study was implemented during the first semester of the academic year $2020 / 2021$.

4- Human limits: The study was applied to an intentional sample of middle school mathematics teachers (eighth grade teachers) in the State of Kuwait.

\section{Terminology of the Study}

- Efficiency: It is the level of impact of the proposed training program in developing the teaching performance of middle school mathematics teachers, and it is measured statistically using the Eta square equation ( $n 2$ ).

-The Training Program: Organized and planned efforts to provide trainees with renewed skills, knowledge and experience, and aim to bring about continuous positive changes in their experiences, attitudes and behavior in order to develop their performance (Al-Taani, 2007: $p$. 14).

The researcher defines it procedurally: it is a set of training sessions with specific goals and includes a set of skills, activities, means, methods and strategies of teaching and assessment, with the aim of developing the teaching performance of eighth grade mathematics teachers. 
- Professional Competencies: Good (Good, 1973:3) defined it as: the ability to achieve the desired results with saving time, effort and expenses.

Medly and Patricia defined professional competencies as: a set of information, skills, and attitudes that enable the teacher to prepare for the educational situation (Medly and Patricia, 1980: 294).

And Patricia defines them as: they are well-defined behavioral goals that describe all the knowledge, skills and attitudes that are believed to be necessary for the teacher if we want to teach effective education. (Patricia, 1975: 293).

The researcher defines professional competencies procedurally as: a system of knowledge, skills, attitudes and values that develop through the learning process, and related to mathematics and related to the performance of the mathematics teacher for the eighth grade, measured by the degree obtained by the study sample members of the level of professional competencies on the questionnaire used in the current study .

- Standards: "Detailed Skills Expectations for Kindergarten to High School Mathematics Grades" (Lujan, 2010:1).

-Teaching Performance: all verbal or skill behavior that an individual emits and is based on a certain cognitive and emotional background, and is usually at a certain level, showing his ability or inability to perform a certain job. (Al-Laqani and Al-Jamal, 1999: p. 21).

Zaytoun (2006) knew him. It is: the ability to perform a specific work / activity related to teaching planning, implementation, and evaluation, and this work is subject to analysis for a group of behaviors (cognitive / motor / social performances), and then it can be evaluated in light of standards of accuracy, speed of achievement, and ability to adapt to Changing teaching situations, using the method of structured observation, which can then be improved through training programs.

The Researcher Defines it procedurally: it is everything that the mathematics teacher does in terms of educational and teaching practices and actions, including planning, implementation and evaluation, and the related processes and responsibilities in the classroom that help him teach the mathematics course for the eighth grade. It is measured by the degree obtained by the study sample members of the level of teaching performance on the observation card tool used in the current study.

-Intermediate Level: It is the third stage of education after primary, early childhood and preschool that follows each other regularly and presents learners with new challenges for their mental, physical, personal, social and moral development. (Committee for Curriculum Development and Preparation of National Standards for Mathematics, 2016).

\section{The Theoretical Framework of the Study}

\section{Professional Competencies (Concept, Importance and Components)}

Zydziunaite (2005) indicated that competence means the ability to make decisions related to a particular professional performance context. Perhaps, he explained the concept of competences introduced by (Pacevicius \& Kekyte, 2008) as a combination of professional knowledge, abilities and skills as well as the ability to apply them according to the requirements of the work environment. Preeti (2017) also emphasized that competence is a 
set of social and communicative learning processes that are nurtured in the post-education stage through the assessment system.

\section{The Importance of Competencies}

(Dubois, 1993, Dainty et al., 2005) stress that competencies are important in the following aspects:

- Competencies are important to teacher performance and success.

- Competencies are important for human resource management.

- Competencies A well-trained workforce that works to achieve the school's organizational goals effectively and efficiently.

\section{Components of Sufficiency}

Preeti (2017) identified four main components of adequacy, which are:

1- Knowledge: This refers to a set of information related to job performance, which is what individuals must know to be able to perform the job, such as knowing the policies and procedures for the recruitment process.

2- Skill: the abilities acquired through practice and it can be a performing skill, or a verbal skill.

3- Personality: The latent characteristics that are brought into the job, and that represent the necessary basis upon which knowledge and skill can be developed.

4- Behavior: It is the apparent and noticeable for some competencies, skills, knowledge and personal traits, that is, it is a final expression mainly of competency in that it is a set of procedures that are supposed to be observed, learned, taught and measured.

\section{Competency-based Education in Teacher Preparation Programs}

Competency-based education and training initiatives focus on self-awareness and metacognition in an experiential learning perspective that supports the transfer of learning outside the classroom. Knowledge-based pedagogy is replaced by competency-based (skills) pedagogy, without being reduced to skills, limiting knowledge, attitudes and behavior while managing emotions associated with experiential learning and the metacognitive process (McEvoy et al., 2005).

\section{A Competency-Based Education Perspective as an Option to Improve Mathematics Teacher Training Programs}

Nadia (2013) suggests some directions for work in the process of improving teacher training programs, related to the meanings of competency-based education:

Rethinking teaching competencies from the perspective of the required learning outcomes in line with the requirements of the knowledge society, in addition to building training programs from the perspective of integrated learning experiences, and linking theory and practice in a real way, inside and outside the classroom, to develop existing training curricula that depend on the epistemological view of learning.

Therefore, the concept of competency-based learning is based on the following main principles regarding mathematics: Carmen \& Smith, 2017)).

- Competency-based learning systems include clearly communicated math learning expectations against which achievement is assessed.

- Formative assessments are linked to those educational expectations, and learners have multiple and varied opportunities to demonstrate learning, and all these common characteristics are supported by research. 
- Clear learning objectives enhance learning for mathematics and have a positive impact on students' perceptions of their learning environment.

- Formative assessment and targeted feedback can support learning, increase academic achievement in mathematics, and allow students to resubmit work.

It can promote positive attitudes towards learning.

\section{Standards}

Mastropieri \& Scruggs (2010) defines standards as written expectations of achieving a given level of performance.

Alfaro, et al, 2013 defines standards as defining what all students are expected to know and able to do in the school environment.

According to Colen (2019) the common features of "learning standards" systems are as follows:

- Learning and teaching standards are organized by specific subject areas (eg mathematics).

- In each subject area, standards are usually organized by grade or grade level.

- The standards include comprehensive, long-term educational goals.

- The criteria are unique to each topic, but there are also commonalities from system to system or from country to country.

\section{Professional Standards for Teaching Mathematics National Council for Teachers of Mathematics (NCTM, 1991)}

The standards are grouped under four main headings: Tasks, Discourse, Environment, and Analysis. These are the main areas of teacher work and shape what happens in mathematics classes. These standards are: (NCTM, 1991)

The First Criterion: Mathematical Tasks Worthy of Attention: by knowing the interests and experiences of students, knowing the range of ways in which diverse students learn, engaging students' thinking, developing students' mathematical understanding and skills, motivating students to make connections, developing a coherent framework for mathematical ideas, and advocating the formulation of mathematical ideas. Problem solving, problem solving, mathematical thinking, enhancing communication about mathematics, representing mathematics as a continuous human activity, and encouraging and developing the behavior of all students to do mathematics.

The Second Criterion: Dialogue: Refers to the methods of representation, thinking, conversation, agreement and disagreement that teachers and students use to participate in these tasks. their ideas orally and in writing and identify what to follow in depth among the ideas that students bring up during the discussion and when and how to associate mathematical symbols and language with students' ideas.

Tools that a math teacher can use to promote dialogue include encouraging and accepting the use of computers, calculators, and other technology, the use of pictures, graphs, tables, and oral presentations.

Standard Three: Environment: represents preparation for learning. It is the unique interaction of intellectual, social, and physical characteristics that shape the ways of knowing and acting that are encouraged and expected in the classroom. This is the context in which tasks and dialogue are combined. 
Standard Four: Analysis of Teaching and Learning: It refers to the continuous monitoring of classroom life, and the extent to which tasks, conversations, and the environment promote the development of knowledge and athletic power for each student. Through this process, teachers examine the relationships between what they do, what their students do, and what they learn.

\section{NCATE National Council for Accreditation of Teacher Education}

The National Council for Accreditation of Teacher Education Standards are: NCATE, 2008

Standard 1: Knowledge This standard requires teachers to have content knowledge, pedagogical content knowledge, skills, and professional behavior necessary to help all students, and they have an in-depth understanding of the content they plan to teach and can provide multiple instructional interpretations and strategies so that all students learn.

Standard 2: Evaluation The unit contains an evaluation system that collects and analyzes data on applicants' qualifications, the performance of candidates and graduates, and the unit's processes to evaluate and improve the performance of candidates, the unit and its programs.

Standard 3: Field Experience and Practice The unit and its school partners design, implement and evaluate field experience and practice so that teacher candidates and other school professionals develop and demonstrate the knowledge, skills, and professional attitudes necessary to help all students learn.

Standard 4: Diversity The unit designs, implements and evaluates curricula and provides expertise to candidates to acquire and demonstrate the knowledge, skills and professional attitudes necessary to assist all students in learning.

Standard 5: Performance The unit systematically evaluates its effectiveness in relation to the candidate's performance. They also cooperate with colleagues in disciplines and schools. The unit also systematically evaluates the performance of faculty members and facilitates professional development.

Standard 6: Resources The unit has leadership, authority, budget, personnel, facilities and resources, including information technology resources, to prepare candidates to meet professional, state and institutional standards.

National Board for Professional Teaching Standards. (NBPTS) National Board for Professional Teaching Standards:

Five core standards of the National Professional Teaching Standards Board have been introduced after their development: (NBPTS, 2016)

1. Teachers are committed to students and their learning:

2. Teachers know what subjects they teach and how to teach those subjects to students:

3. Teachers are responsible for managing and monitoring student learning.

4. Teachers think systematically about their practices and learn from experience.

5. Teachers are members of learning communities. 


\section{Professional Competencies for Teachers}

Based on the theoretical literature, sources and previous studies that were addressed, and what these studies agreed upon, the researcher concluded that the most important competencies that teachers should have while teaching mathematics are:

\section{First, Adequate Planning}

Planning ahead to determine a course of action that can effectively reach goals and objectives is an important first step in any process, and education is no exception. In education, the planning tool is the lesson plan, which is a detailed description of the teacher's instructional cycle in a lesson that aims to help learners achieve a particular learning objective (Ronald, 2009).

\section{Forms of Study Plans}

There are three forms of classroom plans: (Steven, 2010)

- Annual plans are long-term plans. The annual plan, which extends for one year, outlines the process of assembling and sequencing the learning objectives that students will master in the classroom.

- Unit Plans A unit plan plans over a small portion of the year (perhaps a month or six weeks), and is a purposefully grouped set of learning objectives that will be taught together.

- A lesson plan is the details and actions the teacher will take to ensure that the student has achieved a unit learning objective. Lesson plans are the building blocks of a unit plan.

\section{Adequacy of Educational Goals}

Learning objectives are generally classified into three domains: the cognitive domain (knowledge), the psychological domain (skills) and the emotional domain (attitudes). The following is a description of these domains:

\section{First: Benjamin Bloom (Cognitive Domain)}

Learning processes in the cognitive domain include a hierarchy of skills that include processing information, building understanding, applying knowledge, solving problems, and conducting research. It falls under six categories:

1. Knowledge: The ability to recall data and/or information.

2. Understanding: It is the ability to understand the meaning of what is known.

3. Application: the ability to use abstraction or use knowledge in a new situation.

4. Analysis: the ability to distinguish between facts and opinions.

5. Synthesis: the ability to combine different elements or concepts in order to form a pattern so that a new meaning can be established.

6. Evaluation: The ability to reach judgments about the importance of concepts (Bloom et al., 1956)

\section{Second: Affective Domain David Krathwohl}

Most people think of learning as an intellectual or mental function; however, learning is not only a cognitive (mental) function, but can also learn attitudes, behaviors, and physical skills. It includes five categories: 
1. Acceptance and attention: it is awareness of feelings and emotions and the learner's readiness and interests in a specific thing.

2. Response to phenomena: Response is the active participation of the learner.

3. Valuation: Valuation is the ability to see and express the value of something. Evaluation is concerned with the value you attach to a specific object, phenomenon, behavior, or piece of information. This level ranges from simple acceptance to a more complex state of commitment. It is the ability to see the value of something and express it.

4. Organizing: It is the ability to prioritize one value over another and create a unique value system.

5.Value: The ability to internalize values and allow them to control a person's behavior (Kratthwohl et al., 1964).

\section{Third: The Psychomotor Domain Simpson (Psychomotor Domain)}

The psychomotor field is concerned with motor objectives, which are specific to limiting bodily functions, procedures, and explanatory movements. Here we refer to seven categories:

1. Perception: the ability to apply sensory information to motor activity.

2. Preparation: the willingness to perform the performance.

3. Directed response: The ability to imitate the displayed behavior or benefit from trial and error.

4. Mechanism: the ability to convert learned responses into business as usual with efficiency and confidence.

5. Complex overt response: the ability to skillfully perform complex patterns of actions.

6. Adaptation: the ability to modify acquired skills to meet special events.

7. Organization and innovation: creating new kinetic patterns for a specific case (Simpson, 1972).

\section{Second: The Adequacy of the Implementation of the Lesson}

The WIPPEA model for implementing the lesson plan is an acronym that stands for Warm-up, Introduction, Presentation, Practice, Evaluation, Application. The WIPPEA model consists of the following steps:

1) Warm-up / introductory activity: in which previous knowledge is evaluated by reviewing previous materials related to the current lesson.

2) Introduction: It provides a broad overview of the content and concepts to be taught and focuses the learners' attention on the new lesson.

3) Presentation: teaches the content and concepts of the lesson, and this is represented by creating an activity to present the concept or skill.

4) Practice: Models skills and provides opportunities for guided practice, by providing a variety of activities that allow learners to work in groups, pairs or independently to practice the skills, concepts and information provided, and to integrate technology into the available activities.

5) Evaluation: assesses each learner's achievement of the goal, and this is represented by including oral, audio, written or applied performance evaluations.

6) Application: It provides activities that help learners to apply their learning to new situations or contexts that go beyond the lesson and relate to their own lives, by choosing activities that learners can relate to or express. 


\section{Third: The Adequacy of the Assessment}

Assessment is the process of data collection. More specifically, assessment is the ways in which teachers collect data about their teaching and the learning of their students. The data provides a picture of a range of activities using different forms of assessment such as: pre-tests and notes. Once this data is collected, the teacher can then evaluate the student's performance. Therefore, the evaluation relies on the individual's discretion to determine the overall value of the outcome based on the evaluation data. Then the decision-making process, in which the teacher designs ways to improve recognized weaknesses, gaps, or deficiencies (Hanna \& Dettmer, 2004).

\section{Assessment Types}

Diagnostic Assessment is a process by which students' current subject knowledge, skills and abilities are determined, and misconceptions are clarified before teaching takes place. Knowing students' strengths and weaknesses can help them plan better what to teach and how to teach it.

Formative Assessment Formative assessment provides feedback and information during the educational process while learning is taking place. Formative assessment is defined as: formal and informal assessment procedures that teachers conduct during the learning process in order to modify their teaching and learning activities to improve student learning (Lindsey, 2017).

Summative Evaluation Summative evaluation occurs after learning is completed and provides information that summarizes the teaching and learning process. Usually, no further formal learning takes place at this stage, other than casual learning that may occur through completion of projects and tasks.

\section{Literature Review}

Zeynep (2019) conducted a study to assess the teaching practice processes of mathematics teachers and their competencies in mathematics teaching. The study aimed to examine the application process of primary school teachers in primary schools within the scope of a handson course. In addition, the study aimed to assess the teaching competencies in mathematics for teachers by practicing teachers in their schools. The study used the qualitative approach, and the semi-structured interview technique was used as a method of qualitative research. The study sample consisted of (17) primary teachers who were appointed as practicing teachers in the school in which they study. Data were collected through semi-structured interviews with these teachers. As a data collection tool, an interview form prepared by the researcher was used, which includes questions about the application process and mathematics teaching competencies for pre-service teachers who continue training throughout the semester. The results of the study showed that, although the level of professional knowledge of the subject teachers was generally good, it was not noticed that they had competencies in professional skills due to their lack of experience. The results were precisely the same in the level of professional knowledge and skills in mathematics teaching. The results also showed that the pre-service teachers were generally willing to come to the course and willing to cooperate with the teacher, and that the pre-service teachers had a positive relationship with the students in the class. 
An extended study by Li et al (2018) to explore differences in professional adequacy of professional teaching between mathematics and science teachers in primary schools in Taiwan. The study used the descriptive method. The study sample consisted of (1374) mathematics and science teachers. A questionnaire of (105) was used to suffice for the most important professional competencies that teachers with specializations in mathematics and sciences will need and need to develop. The results of the study showed that the professional competence of mathematics and science teachers in this field is relatively weak. While the subjective sufficiency in students' knowledge and understanding of mathematics and science was medium.

Whereas, Elif, et al (2018) study aimed to explore the effect of the lesson study, a professional development model, on mathematics teachers' perceptions of teaching competencies in Turkey. The study used the qualitative method. The study sample consisted of four participants from females and one of them from males. The genders of teachers were not taken into account. Data were collected through semi-structured interviews of middle school mathematics teachers after three research cycles. The results of the study showed that mathematics teachers have the ability to determine competencies in the field of mathematics during the preparation and application of the lesson plan, and they have the ability to use their knowledge of mathematics, and that the adequacy of teaching has become more active with the study of the lesson.

While Julia \& Lars (2017) conducted a study aimed at identifying the impact of the continuing professional development course on mathematics-related competencies for early childhood teachers. and how this course affects the development of early childhood mathematics teachers' knowledge, pedagogical mathematical content, and mathematics beliefs in general. The study used the experimental method. The study sample consisted of (99) kindergarten teachers, they were distributed into two groups, an experimental group (51) a kindergarten teacher, and a control group (48) a kindergarten teacher. The study used a course-style program and the course design was guided by the design principles of the German Center for Teaching Teachers of Mathematics (DZLM), namely, competency orientation, participant orientation, different forms of instruction, cooperation in motivation, and promotion of self-reflection. The results of the study showed that the course served as a learning opportunity for many of the early childhood teachers who participated in it. Participants enhanced their knowledge about promoting sports literacy in informal and formal settings, developing sports literacy and about analyzing and enhancing early sports skills. The results also showed that the course had enhanced competencies, participant orientation, different forms of instruction, cooperation in motivation, and enhanced selfreflection, compared to the control group.

Othman (2016) conducted a study aimed at evaluating the performance of secondary school mathematics teachers in Yemen in light of international standards. The study used the descriptive method. The study sample consisted of 36 mathematics teachers. The study tool is a note card that includes three areas: the field of planning for teaching, the field of teaching implementation, and the field of evaluation. The results of the study showed that the planning domain had an average grade, and the lesson implementation domain was an average grade, while the evaluation domain was a high grade, and the availability of professional standards in the overall performance of mathematics teachers for all fields was an average grade. 


\section{Study Approach}

The current study followed the descriptive approach to determine the competencies and the constructivist approach to building the proposed training program and the quasiexperimental approach, which is represented by the presence of an independent variable (the training program) that will affect the dependent variable represented by teaching performance.

\section{Study Population}

The study population consisted of all middle school mathematics teachers (eighth grade teachers) in the Capital Educational District who work in government schools affiliated with the Education Department for the academic year 2020/2021, and they number 100 according to the official statistics of the Education Department.

\section{The Sample of the Study}

- The Intentional Sample consisted of 70 middle school mathematics teachers (the eighthgrade teachers) with the aim of applying the questionnaire to them to identify the professional competencies that middle school mathematics teachers mastered in the State of Kuwait.

- With regard to the exploratory sample of the study, the researcher applied the study tools represented by the observation card, which were applied to an exploratory sample of 10 middle school mathematics teachers (the eighth grade teachers) from the study community and outside its sample, in order to verify its validity for application to the study sample members. And that by calculating its validity and reliability by appropriate statistical methods. - With regard to the practical aspect of the study (experimental sample) was selected from middle school mathematics teachers (teachers of the eighth grade) consisting of 30 teachers from the study population by the intentional method, who were applied to the study tools represented in the training program.

Study Tool: To achieve the objectives of the study and to answer his questions, the researcher referred to the theoretical literature and previous studies that dealt with the subject of training programs and their impact on the teaching performance of mathematics teachers. A questionnaire of professional competencies to be available for mathematics teachers was built, and then the training program and an observation card were built to measure the teachers' teaching performance.

\section{Validating the Tool Content}

To verify the validity of the study tools, the researcher prepared the questionnaire in its initial form and came up with a list of standards and a scale of competencies that must be met by middle school mathematics teachers. He presented it to a group of arbitrators who specialize in curricula and methods of teaching mathematics, and educational supervisors, and their number reached (10) arbitrators. The criterion of the agreement of seven arbitrators was based on the validity and clarity of the paragraph to remain within the tool, or on the agreement of three arbitrators that it was not clear to amend it. In light of the notes of the arbitrators, the researcher modified the questionnaire, checked the training program and the observation card, and approved the paragraphs agreed upon by the arbitrators. 


\section{Statistical Processors}

- Arithmetic averages and standard deviations of the responses of the research sample members.

- Stability coefficients (Cronbach's alpha).

- Pearson correlation coefficients.

\section{Displaying the Results and Discussion of the Study}

The results of the first question: What are the professional competencies that middle school mathematics teachers in the State of Kuwait should master in light of international standards?

After the researcher reviewed previous studies and theoretical literature related to professional competencies in the light of international standards, in order to determine the most important competencies that must be available to middle school mathematics teachers through a questionnaire, and they were as follows:

A- Determining the Purpose of the Questionnaire: The aim of the questionnaire is to monitor the reality of the availability of professional competencies among middle school mathematics teachers (eighth grade teachers) in the State of Kuwait in order to analyze them and identify weaknesses in the degree of their availability.

B- Determining the list of Professional Competencies: This was done by reviewing the educational literature that dealt with the professional competencies of mathematics teachers and their various classifications, and reviewing the international standards that dealt with the preparation of professional competencies programs for mathematics teachers in the field of planning, implementation and evaluation, as it reached 52 adequacy and after Verification of its validity and stability by applying it to a survey sample and presenting it to a number of arbitrators. The list of competencies has been modified to be 51 adequacies distributed as follows: 19 adequacies in the field of planning, 24 adequacies in the field of implementation, and 8 competencies in the field of evaluation. The objectives are clear when constructing the questionnaire and using paragraphs related to the topic, and that each paragraph contains one idea.

C- Application of the Questionnaire: In light of the foregoing, the questionnaire was applied to the research sample and calculating the arithmetic averages and standard deviations of the responses. The results showed that there are 4 out of 19 adequacy in the field of planning, 6 out of 24 competency in the field of implementation, and 5 out of 8 competencies In the field of evaluation, they came in a low rank, and accordingly the researcher considered that these low competencies are training competencies needed by middle school mathematics teachers in Kuwait. The lack of training courses and programs, and the teachers' lack of interest in inservice training

The results of the second question: What is the proposed training program based on professional competencies in light of international standards for developing the teaching performance of mathematics teachers at the intermediate stage in Kuwait? 
To answer this question, the following steps were taken:

A - Foundations for Building the Program: Through previous studies and research and a review of the theoretical literature, including international standards in the field of building training programs, the following foundations were reached for building the study program:

- Taking into account the nature and characteristics of mathematics teachers.

- Diversification of teaching methods for mathematics.

- Work on developing intellectual and behavioral habits related to dialogue.

- Practicing teamwork inside the training hall and ensuring the cooperation of the trained teachers together.

- Emphasis on strengthening the correct answers for the trained teachers and correcting wrong answers as soon as they occur.

- Inclusion of the program's content with various sports activities that allow taking into account the individual differences among the trained teachers.

- Presenting the contents of the program in the form of interconnected units to arouse the interests of the trained teachers.

- Working on linking the particles with the colleges so that the particles do not lose their value in the proposed training program.

- Work on developing the trainee teacher's ability to clarify professional competencies and link them to the content of mathematics in his own way.

- Emphasizing that the trainee teacher is the main focus when implementing the proposed training program.

- Adopting the structural and continuous evaluation processes for the proposed training program, including diagnostic and therapeutic methods.

- Taking into account the proposed training program in its planning and implementation of the available human and material capabilities.

\section{B - Determine the General Objective of the Proposed Training Program}

- Presenting a model for a proposed training program to develop the teaching performance of middle school mathematics teachers.

- Developing the professional competencies of mathematics teachers in the intermediate stage (the study sample) through training them on these competencies.

\section{C - Determining the Specific Objectives of the Proposed Training Program}

After completing the application of the training program based on professional competencies, it is expected that each trainee of the eighth-grade teachers (experimental sample) and participants in the training program Improving teaching performance.

\section{D - Determine the Target Group}

The category targeted by middle school mathematics teachers (eighth grade teachers) in the State of Kuwait during service who are enrolled in public schools, for the academic year 2020/2021.

\section{E - Basis for Selecting Program Content}

Bases have been adopted for selecting the content of the training program, and these bases are:

- That the content be consistent with the objectives of the program.

- The content should be able to be evaluated. 
- To be diversified.

- To work to achieve the competencies of the profession that have been identified.

\section{F- Determining the Topics of the Proposed Training Program}

The topics that should be available in the training program were identified and included the following:

Unit One: Teaching Planning Competencies: It included the adequacy of tribal learning, the adequacy of formulating educational goals, the adequacy of preparing a daily plan, and the adequacy of time management.

The second unit: Teaching implementation competencies: it included the adequacy of teaching methods, the adequacy of motivation, the adequacy of asking questions, the adequacy of reinforcement, the adequacy of feedback, and the adequacy of closing the lesson.

A third unit: Teaching Evaluation Competencies: It included the adequacy of evaluation, the sufficiency of formative evaluation, the sufficiency of final evaluation, the sufficiency of realistic evaluation, the sufficiency of evaluation strategies, the sufficiency of evaluation evaluation tools (1), and the sufficiency of evaluation- evaluation tools (2).

G- Determining the sessions of the proposed training program: The proposed training program consisted of 19 training sessions

$\mathrm{H}$ - Determining the time of the proposed training program sessions: The program sessions were implemented by the researcher over a period of 9 weeks, at a rate of two sessions per week, and the session time was approximately (45-60) minutes.

\section{I - Determining the teaching and learning aids}

- A laptop computer to display the content of the program (professional competencies) in the form of (power point) presentations.

- Mathematics book for the eighth grade to train the members of the semi-experimental group to apply the professional competencies they learn.

J - Determining the teaching methods to be followed in the proposed training program: Lecture, discussion and collaborative learning Activity-based learning Practical demonstrations Brainstorming Problem solving

K - Determining the educational and learning activities: Drills and exercises Homework Feedback. Discussion Practical presentations for trained teachers: Through the implementation of competencies in a practical performance. Meetings held between teachers trained in professional competencies

$L$ - Determining the methods of evaluating the proposed training program: The evaluation mechanism was determined through the diagnostic evaluation by applying the tribal note card, and then the formative evaluation and that is through the participants' opinions and their reactions about the program. The opinion of the members of the semi-experimental 
group was taken after each training session, by answering the mathematics teachers to evaluation questions about the program's objectives, topics and ways to present each training session. Finally, the dimensional evaluation was addressed after the completion of the training On the performance of professional competencies and after teachers have reached the required level of proficiency, by applying a note card for the practical performance of post-teaching competencies on the members of the quasi-experimental group and comparing the results with the results before applying the program.

M - Validity of the Training Program: The training program was presented to a group of arbitrators who hold a doctorate in mathematics teaching curricula and methods, in addition to a number of 10 mathematics supervisors, and based on the arbitrators' opinions, amendments and recommendations, modifications were made to the proposed training program.

The results of the third question: What is the effectiveness of the proposed training program based on professional competencies in light of international standards in developing the teaching performance of mathematics teachers at the intermediate stage?

The teaching performance note card for professional competencies was built according to the following procedures:

1. Determining the objective of the teaching performance note card for professional competencies: evaluating the level of trained teachers (experimental sample) in the performance aspects of professional competencies before and after implementing the training program based on professional competencies.

2. Description of the Teaching Performance Note Card for Professional Competencies: By reviewing the educational literature and previous studies, the researcher came up with the preparation of a teaching performance note card for professional competencies. By formulating the paragraphs of the teaching performance note card for the professional competencies that fall under each field. The teaching performance observation card for professional competencies in its initial form consisted of 32 competencies, distributed over three areas (teaching planning 9 items, teaching implementation 16 items, teaching evaluation 7 items).

3. The Validity and Reliability of the Teaching Performance Note Card for Professional Competencies: The validity of the teaching performance observation card for professional competencies was verified using the apparent validity by presenting it to 10 specialized arbitrators and their modifications were taken into account. The teaching performance of the professional competencies and the field to which it belongs and the total score of the teaching performance observation card. The stability of the tool was confirmed using the two methods of internal consistency by applying the Cronbach alpha equation to the results of the exploratory sample and the method of agreement of the observers.

4. Correcting the Teaching Performance note Card for Professional Competencies: The teaching performance note card for professional competencies in the final image consisted of (32) adequacy, and the performance of mathematics teachers (experimental sample) was 
observed by three observers based on the scores of the teaching performance note card for professional competencies according to (alternatives) which are: (high - medium - low ), so that those responses were given the following scores: High $=3$ marks, Medium $=2$ marks, Low $=1$ degree. Based on this, the values of the arithmetic averages reached by the results of the study depend on a criterion divided into three equal categories, based on the highest response - the lowest response divided into 3 levels as follows:

$(3-1) \div 3=0.66$

$1-1.66$ low

$1.67-2.33$ average

2.34 - 3 high

The degree of performance of mathematics teachers (experimental sample) was calculated by calculating the arithmetic mean of the total scores of the observers' assessment of professional competencies, and the performance score on the teaching performance observation card for professional competencies ranged between 32-96, so that the low degree reflects the low performance of mathematics teachers, while it expresses High score for high performance on professional competencies.

And to answer the fourth question, which states: "How effective is the proposed training program based on professional competencies in the light of international standards in developing the teaching performance of middle school mathematics teachers?" Arithmetic averages and standard deviations were calculated, and (T.test) was used. ) for the two samples related to the scores of the semi-experimental group members of the study sample (mathematics teachers) on the practical performance note card for the pre and post professional competencies on the sub-domains and the total score of the practical performance note card. Table 1 shows the arithmetic averages and standard deviations before and after the test (T.test) for the two related samples for the scores of the quasiexperimental group members on the practical performance note card for the occupational competencies on the sub-domains and the total score for the note card. 
Table No. (1)

It shows the arithmetic means, standard deviations, pre- and post-test, and the T-test for the two related samples for the scores of the quasi-experimental group members on the performance note card on the sub-domains and the card as a whole.

\begin{tabular}{|c|c|c|c|c|c|c|}
\hline $\begin{array}{l}\text { Level of } \\
\text { statistical } \\
\text { significance }\end{array}$ & $\begin{array}{l}\text { T- } \\
\text { value }\end{array}$ & $\begin{array}{l}\text { Degree } \\
\text { of } \\
\text { freedom }\end{array}$ & $\begin{array}{l}\text { Standard } \\
\text { deviation }\end{array}$ & $\begin{array}{l}\text { Arithmetic } \\
\text { mean }\end{array}$ & Observation & $\begin{array}{l}\text { Domain of } \\
\text { competenci } \\
\text { es }\end{array}$ \\
\hline \multirow{2}{*}{$.014^{*}$} & \multirow{2}{*}{2.62} & \multirow{2}{*}{29} & .27 & 2.11 & tribal & \multirow{2}{*}{$\begin{array}{l}\text { field of } \\
\text { teaching } \\
\text { planning }\end{array}$} \\
\hline & & & .27 & 2.30 & $\begin{array}{l}\text { dimensionali } \\
\text { ty }\end{array}$ & \\
\hline \multirow{2}{*}{$.001^{*}$} & \multirow{2}{*}{3.82} & \multirow{2}{*}{29} & .24 & 1.98 & tribal & \multirow{2}{*}{$\begin{array}{l}\text { Teaching } \\
\text { implementa } \\
\text { tion area }\end{array}$} \\
\hline & & & .37 & 2.20 & $\begin{array}{l}\text { dimensionali } \\
\text { ty }\end{array}$ & \\
\hline \multirow{2}{*}{$.013^{*}$} & \multirow[b]{2}{*}{2.65} & \multirow{2}{*}{29} & .33 & 1.93 & tribal & \multirow{2}{*}{$\begin{array}{l}\text { Teaching } \\
\text { evaluation } \\
\text { field }\end{array}$} \\
\hline & & & .35 & 2.16 & $\begin{array}{l}\text { dimensionali } \\
\text { ty }\end{array}$ & \\
\hline \multirow{2}{*}{$.000^{*}$} & \multirow[b]{2}{*}{5.22} & \multirow[b]{2}{*}{29} & .16 & 2.01 & tribal & \multirow[t]{2}{*}{$\begin{array}{l}\text { Note card as } \\
\text { a whole }\end{array}$} \\
\hline & & & .20 & 2.22 & $\begin{array}{l}\text { dimensionali } \\
\text { ty }\end{array}$ & \\
\hline
\end{tabular}

* Statistically significant at the significance level $(\alpha=0.05)$

Table 1 shows that there are apparent differences between the arithmetic averages and standard deviations between the scores of the quasi-experimental group members of the study sample (mathematics teachers) on the observation card of the practical performance of the professional competencies before and after on the sub-domains and the total score of the note card.

The total score of the observation card for the practical performance of professional competencies has reached the arithmetic mean of the tribal measurement 2.01 standard deviation 16 . In the post measurement it reached 2.22 standard deviation 20 . To identify the significance of these differences, the (T.test) test was used for the two linked samples. Table 1 shows the calculated $(t)$ value; It reached 5.22 with a statistical significance of .000 , which is statistically at the significance level $(\alpha=0.05)$. Between the pre and post measurements on the practical performance observation card for professional competencies, which indicates the impact of the proposed training program based on professional competencies in the light of international standards in developing the teaching performance of mathematics teachers at the intermediate stage in Kuwait. The researcher explained the results of this question to the clear impact of the mutual interactions in the experiences between the members of the 
semi-experimental group, and the reason may be attributed to the link between the content of the proposed training program with the content of mathematics for the eighth intermediate class that teachers apply in their actual teaching, and perhaps this is due to the fact that the topics Sports were presented in the training program with modern and effective teaching methods, the main focus of which is the learner.

These findings of the current study are consistent with the results of the Shield study (2008), which concluded that the training program was effective in developing the professional skills of mathematics teachers. It also agrees with the results of the study Elif, et al, 2018) whose results showed that the adequacy of the implementation of teaching became more active with the process of practical application of mathematics lessons. It also agrees with the results of the study Julia \& Lars (2017), which found that training programs enhance the professional competencies of mathematics teachers. It also agrees with the results of the study (Jennifer, 2015)), which found that training on practical application is an effective way to implement mathematics teaching, and improve classroom practice in mathematics lessons.

\section{Recommendations}

In light of the results of the current study, the researcher recommends the following:

- Directing the attention of those in charge of the Ministry of Education to take advantage of the current study tools, whether the training program, the cognitive achievement test, or the observation card, which will benefit the professional development of mathematics teachers, and raise the level of their teaching performance.

- The necessity of paying attention to the professional competencies of mathematics educators in the intermediate stage, by holding specialized in-service courses that include theoretical and practical mathematical and educational knowledge and information.

- The necessity of adopting modern teaching methods in in-service teacher training and moving away from traditional methods.

- Breaking the gap between theory and practice during training courses for mathematics teachers.

\section{References}

Al-Dara', A. bin B. M. (2008). The effectiveness of a training program based on the use of modern educational techniques in developing the teaching skills of mathematics teachers in Dumat Al-Jandal Governorate, Kingdom of Saudi Arabia." Unpublished Master's Thesis, University of Jordan, Jordan.

Al-Taani, H. A. (2007). The concept of training, its activities, and building training programs, strengthening them. Dar Al-Shorouk for Publishing and Distribution, Amman, Jordan.

Azeem, N., \& Omar, M. K. (2018). Exploring Teacher Performance: A Review of Concepts and Approaches. In DISCLAIMER: The editors of the proceedings of the Graduate Research in Education Seminar (GREduc) (2018) hereby state that the papers that are published in this seminar proceedings were accepted upon review. (p. 108).

Blömeke, S., Busse, A., Kaiser, G., König, J., and Suhl, U. (2016). The relation between content-specific and general teacher knowledge and skills. Teaching and Teacher Education, (56): 35-46. 
Curriculum Development Committee and Preparation of National Mathematics Standards. (2016) Kuwait National Curriculum - Mathematics Curriculum and Standards. The Ministry of Education. Kuwait.

Elif, B. N., Kamuran, A., and Sencer, B. (2018). The Effect of Lesson Study on The perceptions of Mathematics Teachers About Subject Area Competencies. European Journal of Education Studies. Volume 5, Issue 8. 371-394.

$\mathrm{Hu}$, J., Tang, Z., Xu, L., and Wu, Z. (2008). Briefing on MM education, a new way of mathematics teaching. Journal of mathematics Education, (1): (109-113).

Li-C Li-ling, Pi-Yun, C., Hsiao-Lin, T., and Chorng-Jee, G. (2018). Elementary Teachers' Perceptions of Their Professional Teaching Competencies: Differences Between Teachers of Math / Science Majors and Non-math/Science Majors in Taiwan. International Journal of Scions and Math Education. (16): 877-890.

Nair, P. (2017). A Study on Identifying Teaching Competencies and Factors Affecting Teaching Competencies with Special Reference to MBA Institutes in Gujara. A Thesis. Gujarat Technological University Ahmedabad.

National Board for Professional Teaching Standards. (2016). What Teachers Should Know and Be Able to Do: Arlington, Va 22209 1-800-22-Teach.

National Council for Accreditation of Teacher Education. (2008) professional standards Accreditation of Teacher Preparation Institutions for the Massachusetts Avenue, NW.

OECD (Organization for Economic Co-operation and Development). (2010). Are the new millennium learners making the grade? Technology use and educational performance in PISA: Centre for Educational Research and Innovation, OECD.

Osman, A. (2016). Evaluating the performance of secondary school mathematics teachers in Yemen in light of international standards. The Arab Journal of Scientific and Technical Education. University of Science and Technology. (p 5): 85-110.

Zeynep, D. (2019). Assessing the Teaching Practice Processes of Preservice Teachers and Their Competencies of Mathematics Teaching within the Scope of Teaching Practice Course. Universal Journal of Educational Research 7(1): 171-177.

Zeitoun, H. H. (2006). Teaching skills / vision in the implementation of teaching, Cairo: Alam Al-Kutub. 